\title{
Validation of the anti-infective potential of a polyherbal 'Panchvalkal' preparation, and elucidation of the molecular basis underlining its efficacy against Pseudomonas aeruginosa
}

\author{
Chinmayi Joshi ${ }^{1}$, Pooja Patel ${ }^{1}$, Hanmanthrao Palep ${ }^{2}$ and Vijay Kothari ${ }^{1 *}$ (D)
}

\begin{abstract}
Background: A Panchvalkal formulation (Pentaphyte P-5 ${ }^{\oplus}$ ) mentioned in ancient texts of Indian traditional medicine was investigated for its anti-infective potential against Pseudomonas aeruginosa.

Methods: Effect of the test formulation on bacterial growth and pigment production was evaluated by broth dilution assay. In vivo efficacy was evaluated using Caenorhabditis elegans as the model host. Whole transcriptome approach was taken to study the effect of test formulation on bacterial gene expression.

Results: This formulation in vitro was found to be capable of affecting quorum sensing (QS)-regulated traits (pyocyanin, pyoverdine, biofilm) of Pseudomonas aeruginosa. In combination with antibiotics, it enhanced susceptibility of the test bacterium to antibiotics like cephalexin and tetracycline. Effect of Panchvalkal formulation (PF) on QS-regulated traits of $P$. aeruginosa was not reversed even after repeated exposure of the bacterium to PF. In vivo efficacy of PF was demonstrated employing Caenorhabditis elegans as the model host, wherein PF-treated bacteria were able to kill lesser worms than their extract-unexposed counterparts. Whole transcriptome study revealed that approximately $14 \%$ of the P. aeruginosa genome was expressed differently under the influence of PF.

Conclusions: Major mechanisms through which Panchvalkal seems to exert its anti-virulence effect are generation of nitrosative and oxidative stress, and disturbing iron and molybdenum homeostasis, besides interfering with QS machinery. This study is a good demonstration of the therapeutic utility of the 'polyherbalism' concept, so common in ayurved. It also demonstrates utility of the modern 'omics' tools for validating the traditional medicine i.e. ayuromics.
\end{abstract}

Keywords: Quorum sensing, Panchvalkal, Polyherbal, Pseudomonas aeruginosa, Transcriptome, Ayurved, Antimicrobial resistance, Anti-infective

\section{Background}

Pseudomonas aeruginosa, an opportunistic human pathogen, has received consideration throughout the history of modern medicine because it remains consistently present among the top pathogens in lists of common hospital 'superbugs' around the globe. This organism causes acute pulmonary as well as non-pulmonary infections, chronic lung infections, urinary tract infections, and severe

* Correspondence: vijay.kothari@nirmauni.ac.in; vijay23112004@yahoo.co.in

${ }^{1}$ Institute of Science, Nirma University, Ahmedabad 382481, India

Full list of author information is available at the end of the article infections in patients with burns and immunosuppression [1-3]. Recently the World Health Organization (WHO) listed carbapenem resistant $P$. aeruginosa as a 'critical pathogen' in global priority list of antibiotic-resistant bacteria for which new antibiotics are immediately required [4]. P. aeruginosa infection is becoming difficult to treat due to its inherent and acquired resistance to conventional antibiotics and many other antimicrobials. Further, this problem becomes more complex to handle because of the ability of the bacterium to form biofilm and to produce certain virulence factors to cope up with the

(c) The Author(s). 2019 Open Access This article is distributed under the terms of the Creative Commons Attribution 4.0 International License (http://creativecommons.org/licenses/by/4.0/) which permits unrestricted use, distribution, and reproduction in any medium, provided you give appropriate credit to the original author(s) and the source, provide a link to the Creative Commons license, and indicate if changes were made. The Creative Commons Public Domain Dedication waiver (http://creativecommons.org/publicdomain/zero/1.0/) applies to the data made available in this article, unless otherwise stated. 
various stresses employed by the antimicrobials [5]. In $P$. aeruginosa, biofilm formation and virulence factor production are regulated by bacterial cell-to-cell communication mechanism, which is known as Quorum Sensing (QS). QS system of $P$. aeruginosa is complex and it comprises four interconnected signaling systems i.e. las, rhl, pqs, and iqs. las system is at top of the signaling hierarchy, and is responsible for the production of virulence factors such as protease, elastase, exotoxin, biofilm, etc., Furthermore, environmental factors such as phosphate-depletion, iron starvation, and oxygen deprivation can also modulate the expression of QS-associated genes for survival of pathogen in unfavorable conditions $[2,6]$.

Since QS controls major virulence mechanisms in bacterial pathogens, interrupting with intercellular communication has revealed a rational strategy to attenuate their virulence without necessarily killing them. Thus, the modulation of QS is being viewed as an attractive alternative to the conventional antimicrobials. Numerous natural compounds and plant extracts have been reported to possess anti-QS activity [6-12], and the need for natural drugs in treatment of various bacterial infections is being felt increasingly, as they offer lesser side effects. Use of natural drugs is the ancient form of healthcare, and ayurved is one of the traditional therapeutic systems with a well-documented history of hundreds of years, widely practiced in India. Amongst the drug formulation principles of ayurved, 'Polyherbalism'-combination of medicinal herbs is getting popularity worldwide. It offers some benefits that are not available in modern drugs. Polyherbal formulations can serve as potent anti-infective as they contain different phytocompounds that can potentiate the desired biological activity when compatible herbs are formulated together [13].

In present study, we undertook to investigate the effect of a polyherbal preparation described in ayurved as 'Panchvalkal', which has been suggested for treatment of microbial infections viz. vaginal infections and burn wounds [14, 15]. Panchvalkal formulation (PF) used in this study contains the barks of different Ficus species, mentioned in the treatment of inflammations, abscess and wounds [16]. Various biological activities/ applications of Panchvalkal like vranaprakshalana (cleaning of wound with a liquid agent), vranaropana (healing of ulcer), shothahara (anti-inflammatory; reducing oedema or swelling), upadanshahara and visarpahara (elimination of rash/ blisters typical of sexually transmitted infections) are described in ayurvedic texts namely Charak Samhita, Bhava Prakasha Nighantu, and Sharangadhara Samhita. In our previous study, we reported QS-modulatory activity of PF against Chromobacterium violaceum, Serratia marcescens and Staphylococcus aureus [17].

We tested this formulation against $P$. aeruginosa, for its QS-modulatory (QSM) potential. Following demonstration of its in vitro QSM potential, we assayed it for in vivo efficacy using the nematode Caenorhabditis elegans as a model host. To decipher the molecular basis of its efficacy, whole transcriptome analysis of $P$. aeruginosa exposed to 'Panchvalkal' was done; its gene expression profile in presence of 'Panchvalkal' was compared with that in its absence. This study is a demonstration of the role of bacterial QS machinery as an important target for development of new antimicrobials/ anti-infectives, and also of the effective use of modern 'omics' for validation of ayurvedic prescriptions i.e. ayuromics.

\section{Methods \\ Bacterial strain}

Culture of $P$. aeruginosa was obtained from Microbiology Department, M.G. Science Institute, Ahmedabad. Pseudomonas agar (HiMedia, Mumbai) was used for the maintenance of the culture. Antibiotic susceptibility profile of the bacterium was generated using the antibiotic discsDodeca Universal-I, Dodeca G-XI Minus, and Icosa Universal-2 (HiMedia, Mumbai). This strain of $P$. aeruginosa was found to be resistant to amoxicillin $(30 \mu \mathrm{g})$, cefadroxil $(30 \mu \mathrm{g})$, ampicillin $(10 \mu \mathrm{g})$, cloxacillin $(1 \mu \mathrm{g})$, penicillin $(10 \mu \mathrm{g})$, chloramphenicol $(30 \mu \mathrm{g})$, cefixime $(5 \mu \mathrm{g})$, clindamycin $(2 \mu \mathrm{g})$, and nitrofurantoin $(300 \mu \mathrm{g})$.

\section{Test formulation}

Capsules of Panchvalkal extract (Pentaphyte $\mathrm{P}^{\circ}$ ) containing mixtures of bark extracts of Ficus bengalensis, Ficus religiosa, Ficus racemosa, Ficus lacor, and Albizzia lebbec, were procured from Dr. Palep's Medical Research Foundation Pvt. Ltd., Mumbai. Powder contained inside the capsules was dissolved in DMSO (Merck, Mumbai) for bioassay. Starch and talk, which are part of the capsule content $(22 \% \mathrm{w} / \mathrm{w}$ and $2 \% \mathrm{w} / \mathrm{w}$ respectively), were confirmed to have no effect on measured microbiological parameters.

\section{Broth dilution assay}

Assessment of QS-regulated pigment production by $P$. aeruginosa in presence or absence of the test formulation, was done using broth dilution assay [18]. Organism was challenged with different concentrations (250$1000 \mu \mathrm{g} / \mathrm{mL}$ ) of Panchvalkal extract. Pseudomonas broth (peptic digest of animal tissue $20 \mathrm{~g} / \mathrm{L}$, potassium sulphate $10 \mathrm{~g} / \mathrm{L}$, magnesium chloride $1.4 \mathrm{~g} / \mathrm{L}, \mathrm{pH} 7.0 \pm 0.2$ ) was used as a growth medium. Inoculum standardized to 0.5 McFarland turbidity standard was added at $10 \% \mathrm{v} / \mathrm{v}$, followed by incubation at $37{ }^{\circ} \mathrm{C}$ for $22-24 \mathrm{~h}$, with intermittent shaking. Appropriate vehicle control containing DMSO was also included in the experiment, along with abiotic control (containing extract and growth medium, but no inoculum). Catechin (50 $\mathrm{gg} / \mathrm{mL}$; Sigma Aldrich) was used as positive control. 
Measurement of bacterial growth and pigment estimation At the end of the incubation, bacterial growth was quantified photometrically by measuring the culture density at $764 \mathrm{~nm}$ wavelength [19]. This was followed by pigment extraction and quantification, as per the method described below for each of the pigment. Purity of each of the extracted pigment was confirmed by running a UV-vis scan (Agilent Cary 60 UV-visible spectrophotometer). Appearance of single major peak (at the $\lambda_{\max }$ reported in literature) was taken as indication of purity.

\section{Pyoverdine [20] and pyocyanin [21] extraction}

One $\mathrm{mL}$ of the culture broth was mixed with chloroform (Merck, Mumbai) in 2:1 proportion followed by centrifugation at $12,000 \mathrm{rpm}(15,300 \mathrm{~g})$ (REMI CPR-24 Plus) for $10 \mathrm{~min}$. This resulted in formation of two immiscible layers. OD of the upper water-soluble phase containing yellow-green fluorescent pigment pyoverdine was measured at $405 \mathrm{~nm}$. Pyoverdine Unit was calculated as $\mathrm{OD}_{405} / \mathrm{OD}_{764}$. This parameter was calculated to nullify the effect of change in cell density on pigment production.

The lower chloroform layer containg pyocyanin was mixed with $0.1 \mathrm{~N} \mathrm{HCl}$ (Merck; at the rate of $20 \% \mathrm{v} / \mathrm{v}$ ), resulting in a colour change from blue to pink. Absorbance of this pyocyanin in acidic form was measured at $520 \mathrm{~nm}$. Pyocyanin Unit was calculated as $\mathrm{OD}_{520} / \mathrm{OD}_{764}$.

\section{Hemolysis assay [22]}

OD of overnight grown culture was standardized to 1.00 at $764 \mathrm{~nm}$. Cell free supernatant was prepared by centrifugation at $15,300 \mathrm{~g}$ for $10 \mathrm{~min} .10 \mu \mathrm{L}$ of human blood (sourced from authors' own body in healthy condition under no antibiotic treatment; collected in heparinized vial) was incubated with this cell free supernatant for $2 \mathrm{~h}$ at $37^{\circ} \mathrm{C}$, followed by centrifugation at $800 \mathrm{~g}$ for $15 \mathrm{~min}$. $1 \%$ Triton $\mathrm{X}-100$ (CDH, New Delhi) was used as positive control. Phosphate buffer saline (PBS; pH 6.8) was used as negative control. OD of the supernatant was read at 540 $\mathrm{nm}$, to quantify the amount of haemoglobin released.

\section{Assay of bacterial susceptibility to lysis in presence of human serum [23]}

Serum was separated by centrifuging blood at $1500 \mathrm{rpm}$ $(800 \mathrm{~g})$ for $10 \mathrm{~min}$. Bacterial culture grown in media with and without PF was centrifuged, and the cell pellet was reconstituted in $\mathrm{PBS}$, so that the resulting suspension attains $\mathrm{OD}_{764}=1.200 \mu \mathrm{l}$ of this bacterial suspension from control or experimental tubes was mixed with $740 \mu \mathrm{l}$ of PBS and $60 \mu \mathrm{l}$ of serum. After incubation for $24 \mathrm{~h}$ at $37^{\circ} \mathrm{C}$, absorbance was read at $764 \mathrm{~nm}$. DMSO $(0.5 \% v / v)$-treated cells suspended in PBS served as control, against which OD of the PF-treated cells (serum-exposed) was compared. Tubes containing bacterial cells exposed neither to DMSO nor serum were also included in the experimental set-up, to nullify any interference from autolysis.

\section{Catalase assay}

OD of the overnight grown bacterial culture was adjusted to 1.00 at $764 \mathrm{~nm} .400 \mu \mathrm{L}$ of phosphate buffer was added into a $2 \mathrm{~mL}$ vial followed by $400 \mu \mathrm{L} \mathrm{H} \mathrm{H}_{2} \mathrm{O}_{2}$. To this $200 \mu \mathrm{L}$ of the bacterial culture was added, and the mixture was incubated for $10 \mathrm{~min}$. Then $10 \mu \mathrm{M}$ of sodium azide was added to stop the reaction [24], followed by centrifugation at $12,000 \mathrm{rpm}(15,300 \mathrm{~g})$ for $10 \mathrm{~min}$. OD of the supernatant was measured at $240 \mathrm{~nm}$ to quantify remaining $\mathrm{H}_{2} \mathrm{O}_{2}$ [25], with phosphate buffer as blank.

\section{Assay for testing extract's ability to inhibit biofilm formation, eradicate pre-formed biofilm and affect the biofilm-viability}

In this assay, control and experimental, both groups contained nine test tubes. In each group, three subgroups were made. First subgroup of three test tubes in the experimental group contained Pseudomonas broth supplemented with PF $(750 \mu \mathrm{g} / \mathrm{mL})$, whereas remaining six tubes contained Pseudomonas broth with no PF on first day of experiment. All these tubes were inoculated with inoculum $(10 \% \mathrm{v} / \mathrm{v})$ standardized to $0.5 \mathrm{McFarland}$ turbidity standard (making total volume in tube $1 \mathrm{~mL}$ ), followed by incubation at $37^{\circ} \mathrm{C}$ for $24 \mathrm{~h}$ under static condition, which resulted in formation of biofilm as a ring on walls of the glass tubes. This biofilm was quantified by crystal violet assay [26], preceded by quantification of bacterial cell density and pigment.

Content from the remaining six test tubes from rest of the two subgroups were discarded following cell density and pigment estimation, and then the biofilms remaining on inner surface of these tubes were washed with phosphate buffer saline (PBS; pH 7) to remove loosely attached cells. Now, $2 \mathrm{~mL}$ of minimal media (Sucrose 15 $\mathrm{g} / \mathrm{L}, \mathrm{K}_{2} \mathrm{HPO}_{4} 5.0 \mathrm{~g} / \mathrm{L}, \mathrm{NH}_{4} \mathrm{Cl} 2 \mathrm{~g} / \mathrm{L}, \mathrm{NaCl} 1 \mathrm{~g} / \mathrm{L}, \mathrm{MgSO}_{4}$ $0.1 \mathrm{~g} / \mathrm{L}$, yeast extract $0.1 \mathrm{~g} / \mathrm{L}, \mathrm{pH} 7.4 \pm 0.2$ ) containing $\mathrm{PF}$ $(750 \mu \mathrm{g} / \mathrm{mL})$, was added into each of these tubes, so as to cover the biofilm completely, and tubes incubated for $24 \mathrm{~h}$ at $37^{\circ} \mathrm{C}$. At the end of incubation, one subgroup of 3 tubes was subjected to crystal violet assay to know whether any eradication of the pre-formed biofilm has occurred under the influence of PF, and the last subgroup of 3 tubes was subjected to viability assessment through MTT assay.

For the crystal violet assay, the biofilm- containing tubes (after discarding the inside liquid) were washed with PBS in order to remove all non-adherent (planktonic) bacteria, and air-dried for $15 \mathrm{~min}$. Then, each of the washed tubes was stained with $1.5 \mathrm{~mL}$ of $0.4 \%$ aqueous crystal violet solution for $30 \mathrm{~min}$. Afterwards, each tube was washed twice with $2 \mathrm{~mL}$ of sterile distilled 
water and immediately de-stained with $1500 \mu \mathrm{L}$ of $95 \%$ ethanol. After $45 \mathrm{~min}$ of de-staining, $1 \mathrm{~mL}$ of de-staining solution was transferred into separate tubes, and read at $580 \mathrm{~nm}$.

For the MTT assay [27], the biofilm- containing tubes (after discarding the inside liquid) were washed with PBS in order to remove all non-adherent (planktonic) bacteria, and air-dried for $15 \mathrm{~min}$. Then $900 \mu \mathrm{L}$ of minimal media was added into each tube, followed by addition of $100 \mu \mathrm{L}$ of $0.3 \%$ MTT [3-(4,5-Dimethylthiazol-2-yl)-2,5-Diphenyltetrazolium Bromide, HiMedia]. After $2 \mathrm{~h}$ incubation at $37^{\circ} \mathrm{C}$, resulting purple formazan derivatives were dissolved in DMSO and measured at $540 \mathrm{~nm}$.

\section{Determination of the effect of PF on antibiotic susceptibility of the test organism}

After in vitro assessment of QSM property of the test formulation, effect of this PF on antibiotic susceptibility of the test pathogen was investigated. This investigation was done in two different ways. In one set of experiments, we challenged the test pathogen with PF and antibiotic simultaneously, wherein susceptibility of test pathogens to sub-MIC concentration of different antibiotics in absence and presence of test formulation was assessed through broth dilution assay. In another set of experiments the bacterial cells pre-treated with PF were subsequently challenged with antibiotic. All the antibiotics were procured from HiMedia, Mumbai.

\section{In vivo assay [28]}

In vivo efficacy of the test formulation at the concentration(s) found effective during in vitro screen was evaluated using the nematode worm Caenorhabditis elegans as the model host. This worm was maintained on Nematode Growing Medium (NGM; $3 \mathrm{~g} / \mathrm{L} \mathrm{Nacl,} 2.5 \mathrm{~g} / \mathrm{L}$ peptone, $1 \mathrm{M} \mathrm{Cacl}_{2}, 1 \mathrm{M} \mathrm{MgSO} 4,5 \mathrm{mg} / \mathrm{mL}$ cholesterol, $1 \mathrm{M}$ phosphate buffer of $\mathrm{pH} 6,17 \mathrm{~g} / \mathrm{L}$ agar-agar) with $E$. coli OP50 as the feed. Worm population to be used for the in vivo assay was kept on NGM plates not seeded with E. coli OP50 for three days.

Test bacterium was incubated with the PF for $24 \mathrm{~h}$. Following incubation, OD of the culture suspension was equalized to that of the DMSO control. $100 \mu \mathrm{L}$ of this bacterial suspension was mixed with $900 \mu \mathrm{L}$ of the M9 buffer containing 10 worms (L3-L4 stage). This experiment was performed in 24-well (sterile, non-treated) polystyrene plates (HiMedia), and incubation was carried out at $22^{\circ} \mathrm{C}$. Number of live vs. dead worms was counted everyday till 5 days by putting the plate (with lid) under light microscope (4X). Standard antibiotic and catechin treated bacterial suspension were used as positive control. Straight worms were considered to be dead, and lack of movement in the 'dead' looking worms was confirmed by tapping the plates. On last day of the experiment, when plates could be opened, their death was also confirmed by touching them with a straight wire, wherein no movement was taken as confirmation of death.

\section{Whole transcriptome analysis RNA isolation, library preparation, and sequencing}

RNA was extracted from bacterial cell pellet using $\mathrm{Hi}$ PURA Bacterial RNA Purification kit (HiMedia, USA) followed by measurement of concentration using QubIT and QC analysis using RNA 6000 Nano Bioanalyzer kit. Whole transcriptome library was prepared from QC qualified samples (RIN > 7) using NEB next ultra RNA library preparation kit (NEB). In brief, $10 \mu \mathrm{g}$ of Total RNA was taken for ribosomal RNA depletion using Ribominus Bacteria kit module (Invitrogen Inc., USA). The rRNA depleted samples were fragmented using enzymatic method. First strand cDNA synthesis was done using random primers followed by second strand cDNA synthesis, end repair and adapter ligation. The adapter ligated libraries were multiplexed by adding index sequences via amplification. The adapter ligated and indexed libraries were quantitated by QubIT and validated by using Agilent HS kit. Resulting validated libraries were pooled in equimolar ratio and sequenced on NextSeq500 platform (Illumina, USA) using 2x150bp chemistry. The raw data was processed further after necessary quality check with an average Q30 > 70\%. All the raw sequence data has been submitted to Sequence Read Archive. Relevant accession no. are SRX2855033 and SRX2855034.

\section{Genome annotation and functional analysis Read quality check analysis and mapping}

QC report of obtained sequences was generated using FastQC application. The high-quality reads were mapped to the reference genome of $P$. aeruginosa PAO1 (NCBI accession no. NC_002516) using RNASeq analysis protocol of CLC Genomics Workbench version 9.0.

\section{Differential gene expression analysis}

The count data was compared between the samples to identify the differentially expressed genes. The number of reads mapping to each gene was summarised as count data. The count data was first normalised by applying quantile normalization tool in CGWB version 9.0. The count data was further statistically analysed using Kal's Z-test integrated into CGWB. Genes exhibiting $p$ value $\leq 0.05$ were filtered as either up- or down- regulated genes, which were then looked for in panther database for gene ontology classification.

\section{Statistical analysis}

All the experiments were performed in triplicate, and measurements are reported as mean \pm standard deviation 
(SD). Statistical significance of the data was evaluated by applying $t$-test using Microsoft Excel ${ }^{\circ} . p$ values $\leq 0.05$ were considered to be statistically significant.

\section{Results}

In vitro studies

PF modulates the production of QS-regulated pigments

Pyoverdine production was enhanced at all the test concentrations, whereas pyocyanin production was enhanced at the lowest $(250 \mu \mathrm{g} / \mathrm{mL})$ and highest $(1000 \mu \mathrm{g} /$ $\mathrm{mL}$ ) test concentrations, and reduced at the intermediate concentrations of PF (Fig. 1a). Effect of PF on QS-regulated pigments in $P$. aeruginosa was not found to be dosedependent. Such dose-independent response may be for the reason that same plant compounds present in a given extract can interact differently at different concentrations, to produce different biological effect. Bacterial growth was not affected significantly at any of the test concentrations, and hence the effect of PF on P. aeruginosa can be said to be purely quorum-modulatory. In fact, an ideal quorum modulator is expected to exert its effect on susceptible pathogens with minimum or no effect on growth [29]. Increased pyoverdine production in the PF-exposed $P$. aeruginosa can be taken as an indication of disturbance of iron homeostasis, as pyoverdine is a known siderophore [30]. Since pyocyanin, whose production was reduced at 500 and $750 \mu \mathrm{g} / \mathrm{mL} \mathrm{PF}$, is an important virulence factor [31], these two concentrations were chosen for further experiments.

\section{PF affects the catalase activity, and haemolytic potential of the bacterium}

QS system of $P$. aeruginosa has been reported to be involved in regulation of antioxidant enzymes like catalase, superoxide dismutase, etc. [32]. Organism can be expected to be under stress in presence of an effective QSM. Hence, we estimated catalase activity of $P$. aeruginosa in absence and presence of PF, and found it to be enhanced by PF to a minor but statistically significant extent (Table 1). Higher catalase activity can be taken as an indication of the organism facing oxidative stress.

Hemolytic potential, another clinically relevant virulence trait of many infectious bacteria including $P$. aeruginosa [33], was found to be curbed in the range of $\sim 8-16 \%$ upon exposure of this pathogen to PF (Table 1).

\section{PF enhances susceptibility of $P$. aeruginosa to lysis in presence of human serum}

PF enhanced $P$. aeruginosa killing by $\sim 19 \%$ when incubated with freshly isolated human serum (Fig. 1b), indicating ability of Panchvalkal to impair $P$. aeruginosa resistance to human serum. This can possibly be an additional mechanism by which Panchvalkal may confer protection to infection inside human body. This lysis-enhancing trait of PF can be of help to human immune system while fighting infection. We may speculate (however, it needs to be validated experimentally) that the cell surface hydrophobicity of $P$. aeruginosa perhaps gets modulated, when challenged with PF, as the surface hydrophobicity has been shown to be an important determinant for bactericidal action of human serum against $P$. aeruginosa [34]. It may be noted that enhancing the sensitivity of $P$. aeruginosa to serum, through fever induction has been known to be one of the host defense mechanisms against such bacterial infections [35].

\section{PF inhibits biofilm formation, but does not reduce its viability}

PF $(750 \mu \mathrm{g} / \mathrm{mL})$ inhibited biofilm formation in $P$. aeruginosa by $26.50 \%$ (Fig. 1c). However, it could not eradicate pre-formed biofilm $P$. aeruginosa biofilm. On the contrary, OD of the crystal violet trapped by biofilm in eradication assay was $16.45 \%$ higher in the PF-treated culture, which is difficult to explain. Similar increase in biofilm mass of cinnamaldehyde-treated Staphylococcus aureus was reported by Ferro et al., 2016 [23], which they attributed to accumulation of dead cells inside biofilm matrix. However, similar explanation can not be applied to results of this study, as PF had no effect on viability of $P$. aeruginosa biofilm (Fig. 1c). It may be speculated that PF applied on planktonic cells is inhibiting biofilm formation, whereas that applied on biofilm is somehow promoting the biofilm matrix synthesis. In fact, few genes ( $p s l K$, retS) associated with polysaccharide synthesis/ pilus expression were found to be up-regulated in the whole transcriptome study described in later part of the paper.

\section{PF modulates the susceptibility of $P$. aeruginosa to different antibiotics}

To investigate whether PF can alter antibiotic susceptibility profile of $P$. aeruginosa, we took four antibiotics (ofloxacin, gentamicin, tetracycline, and cephalexin) belonging to different classes i.e. fluoroquinolone, aminoglycoside, tetracyclines, and cephalosporins. PF $(500 \mu \mathrm{g} /$ $\mathrm{mL}$ ), when used together with antibiotic, made $P$. aeruginosa more susceptible to all the test antibiotics, except ofloxacin. Against latter, its susceptibility was reduced a bit $(\sim 7 \%)$, however this reduction in susceptibility disappeared when PF was used at higher concentration $(750 \mu \mathrm{g} / \mathrm{mL})$ along with antibiotic. Magnitude of alteration in susceptibility to all the tested antibiotics differed at both the PF concentrations used (Fig. 1d-e). These results indicate the potential of Panchvalkal as an adjuvant to conventional antibiotic therapy, as already indicated in one of our previous reports [36]. PF pre-treatment of the bacterium before being challenged with these antibiotics did not affect its susceptibility, except in case of cephalexin (Fig. 1f). 

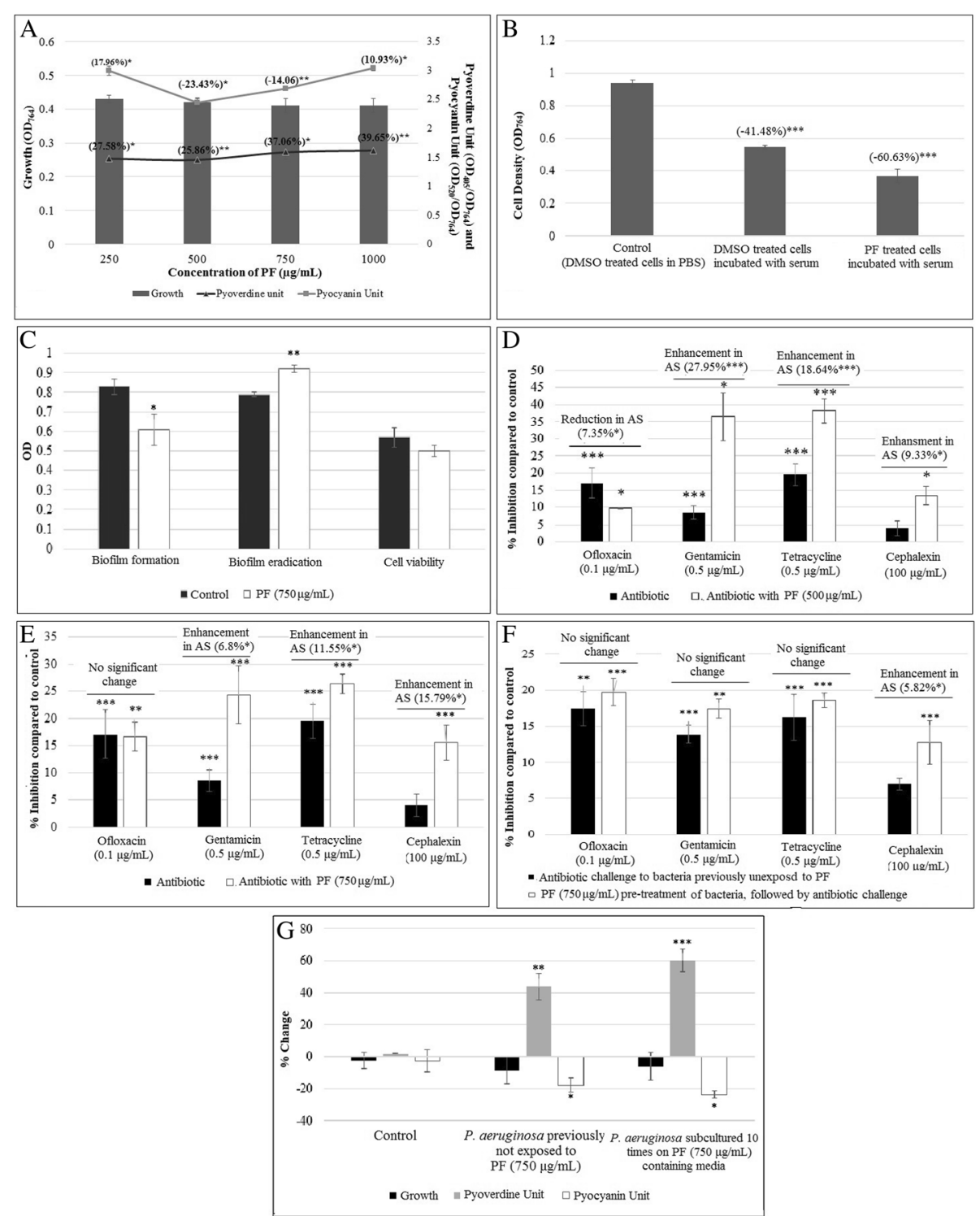

Fig. 1 Effect of Panchvalkal formulation (PF) on various traits of P. aeruginosa, in vitro. a. Effect of PF on growth and QS-regulated pigment production in $P$. aeruginosa. b. PF enhances susceptibility of $P$. aeruginosa to lysis in presence of human serum. c. Effect of PF $(750 \mu \mathrm{g} / \mathrm{mL})$ on $P$. aeruginosa biofilm formation, eradication, and viability. d. P. aeruginosa challenged with PF $(500 \mu \mathrm{g} / \mathrm{mL})$ and antibiotic together. e. P. aeruginosa challenged with PF $(750 \mathrm{\mu g} / \mathrm{mL})$ and antibiotic together. f. $P$. aeruginosa challenged with antibiotic following pre-treatment with PF. g. Effect of PF on P. aeruginosa growth, pyoverdine unit, and pyocyanin unit remained unaltered after repeated exposure to PF. Bacterial growth was measured as $O D_{764 ;} O D$ of pyoverdine was measured at $405 \mathrm{~nm}$, and Pyoverdine Unit was calculated as the ratio $\mathrm{OD}_{405} / \mathrm{OD}_{764}$ (an indication of pyoverdine production per unit of growth), Pyocyanin Unit was calculated as the ratio $\mathrm{OD}_{520} / \mathrm{OD}_{764}$ (an indication of pyocyanin production per unit of growth); 'Control' in this figure is the 'vehicle control' representing the \% change values in comparison to the 'growth control' i.e. tube containing only growth medium plus organism, but no DMSO; 0.5\% v/v DMSO used as 'vehicle control' did not affect biofilm of the bacterium; Crystal violet assay was performed to measure biofilm formation, and biofilm eradication, followed by the measurement of OD at $580 \mathrm{~nm}$; Cell viability in biofilm was estimated through MTT assay, wherein OD was measured at $540 \mathrm{~nm} ;{ }^{*} p<0.05,{ }^{* *} p<0.01,{ }^{* *} p<0.001$

\section{In vivo study}

PF confers survival benefit on C. elegans, when challenged with $P$. aeruginosa

After confirming in vitro QSM effect of PF against $P$. aeruginosa, we tested its in vivo efficacy, employing the nematode worm $C$. elegans as the model host. P. aeruginosa un-exposed to PF could kill $80 \%$ of the worm population by fifth day, wherein $70 \%$ were killed just by second day post-infection; whereas that pre-treated with PF (500 or $750 \mu \mathrm{g} / \mathrm{mL}$ ) could kill only 30 and $10 \%$ worms respectively, by fifth day (Fig. 2). Onset of death in worm population was also delayed by 3 days, in case of $P$. aeruginosa 
Table 1 Effect of PF on catalase and haemolytic activity of P. aeruginosa

\begin{tabular}{lll}
\hline $\begin{array}{l}\text { Concentration } \\
(\mu \mathrm{g} / \mathrm{mL})\end{array}$ & $\begin{array}{l}\text { Catalase activity } \\
(\% \text { change) }(\text { Mean } \pm \mathrm{SD})\end{array}$ & $\begin{array}{l}\text { Haemolytic activity } \\
(\% \text { change) (Mean } \pm \mathrm{SD})\end{array}$ \\
\hline 500 & $1.52^{* *} \pm 0.67$ & $-8.45^{*} \pm 3.48$ \\
750 & $2.14^{* *} \pm 0.24$ & $-15.58^{*} \pm 5.20$
\end{tabular}

${ }^{*} p<0.05,{ }^{* *} p<0.01,{ }^{* * *} p<0.001$; '-'sign indicates a decrease over control; DMSO in 'vehicle control' tube had no effect on catalase and haemolytic activity of the bacterium

pre-exposed to $750 \mu \mathrm{g} / \mathrm{mL}$. In fact, the worm population proliferated beyond the start count of 10 (progeny count not recorded).

In addition to challenging $C$. elegans with PF-pretreated $P$. aeruginosa, we also did an additional experiment, wherein $C$. elegans already infected with $P$. aeruginosa (not previously exposed to $\mathrm{PF}$ ) were put in liquid medium containing PF $(750 \mu \mathrm{g} / \mathrm{mL})$. Survival benefit conferred by PF on $C$. elegans in this experiment (Additional file 1: Table S5) was statistically identical to that described in preceding paragraph.

Once we witnessed the appreciable anti-infective potential of PF in vitro and in vivo, we proceeded to investigate whether $P$. aeruginosa can develop resistance to this formulation upon repeated exposure. For this, the test pathogen was subcultured 10-times on PF $(750 \mu \mathrm{g} /$ $\mathrm{mL}$ )-containing media, and this culture (having multiple exposure to PF) was allowed to infect C. elegans. Worm population challenged with this bacterial culture registered a survival of $100 \%$ (Fig. 2), equivalent to the 'control' worm population not challenged with any pathogenic bacteria. In vitro response of $P$. aeruginosa to PF also was not found to alter, even after repeated exposure to this polyherbal formulation (Fig. 1g). Bacteria may find it difficult to develop resistance against multicomponent preparations, as different components of such formulations can simultaneously affect multiple targets in bacteria, involving more than one mechanisms.

\section{Whole transcriptome analysis of PF-treated $P$. aeruginosa}

A comparative analysis of 'control' $P$. aeruginosa culture with that exposed to PF $(750 \mu \mathrm{g} / \mathrm{mL}$; equivalent to $567 \mu \mathrm{g} / \mathrm{mL}$ of plant extract) in context of gene expression at the whole transcriptome level, resulted in identification of 5698 genes; of which 1602 (28.11\% of total) were expressed differentially in the PF-treated culture at $p$-value less than or equal to 0.05 . However, to have greater confidence in our interpretation of the data, we applied the dual criteria of $p \leq 0.05$ and fold-change value $\geq 1.5$. In total, there were 787 (13.81\% of total) genes satisfying these dual criteria. Of these 787 genes, 389 were down-regulated (Additional file 1: Table S1), and 398 were up-regulated (Additional file 1: Table S2). Fold change values of the up-regulated genes ranged till 16.83, and those for down-regulated ones ranged till 8.77. Additionally a total of 12 genes were found expressed exclusively in the experimental culture (Additional file 1: Table S3). Information on function of all these genes was sourced from KEGG database [37].

\section{Discussion}

A function-wise categorization of significantly differentially expressed genes is presented in Fig. 3. List of genes in each of these categories is given in Additional file 1: Table S4. Among the top 35 down-regulated genes, five (PA0521, norB, norC, PA0525, nirQ) were coding for nitric oxide reductase (NOR), whose major function is to detoxify NO generated by nitrite reductase (NIR). Nitric oxide (NO) is a toxic byproduct of anaerobic respiration in $P$. aeruginosa. Though NO toxicity mechanism(s) are

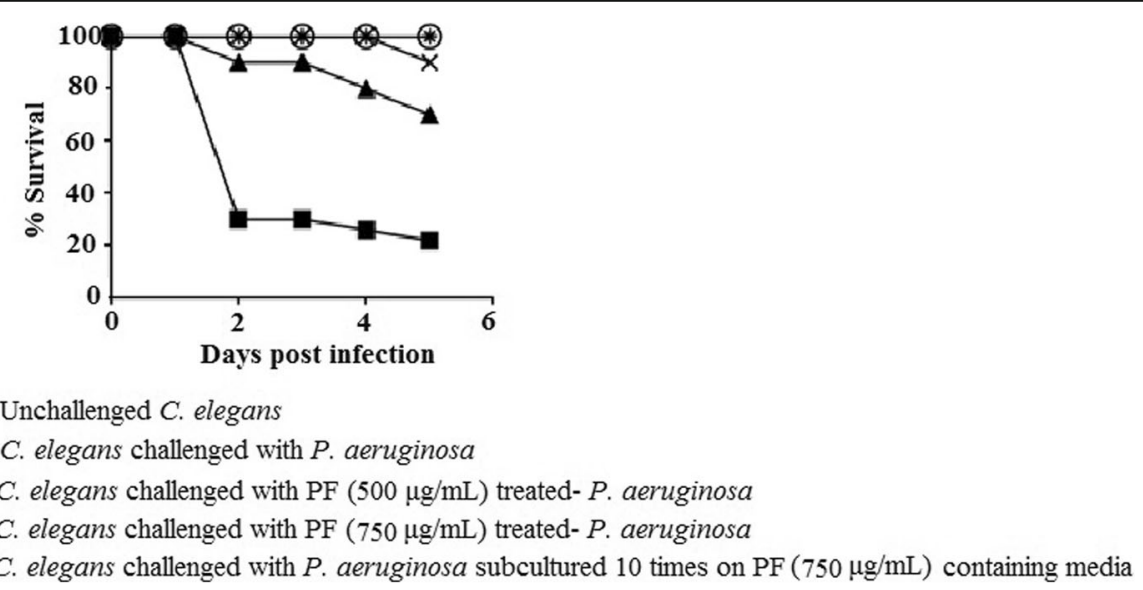

Fig. 2 Survival curve showing the protective effect of PF $(750 \mu \mathrm{g} / \mathrm{mL})$ on C. elegans, when challenged with $P$. aeruginosa. Catechin $(50 \mu \mathrm{g} / \mathrm{mL})$ and Gentamicin $(0.1 \mu \mathrm{g} / \mathrm{mL})$ employed as positive controls conferred 100 and $80 \%$ protection respectively. DMSO present in the 'vehicle control' at $0.5 \% \mathrm{v} / \mathrm{v}$ neither affected virulence of the bacterium towards C. elegans, nor showed any toxicity towards, worm 

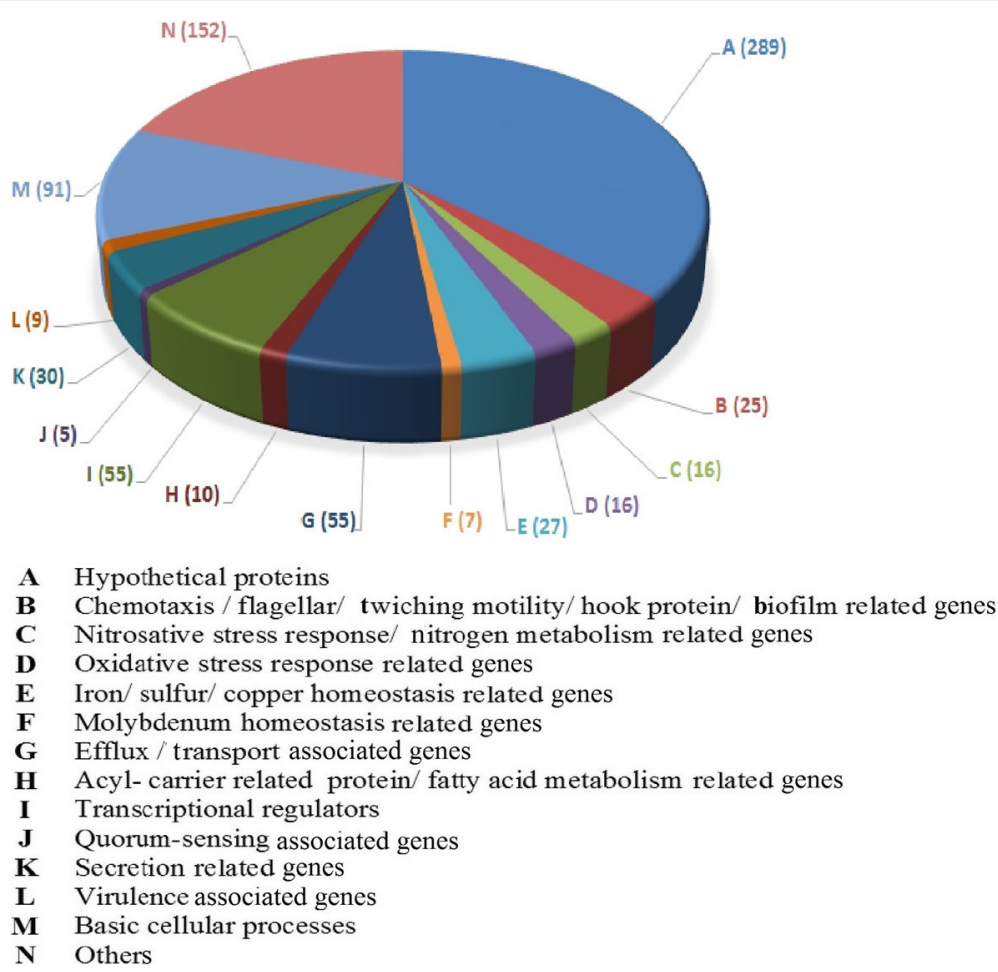

Fig. 3 Function-wise categorization of the significantly differentially expressed genes in Panchvalkal-treated P. aeruginosa

not clearly understood, available evidence indicates that NO-derived nitrosative species can damage DNA, and compromise protein function. In denitrifying bacteria, the denitrification pathway is tightly regulated to minimize the adverse effects of NO [38]. P. aeruginosa has two nitric oxide (NO)-detoxification enzymes, NOR and flavohemoglobin [39]. The potency of high intracellular NO was demonstrated by showing that a mutant lacking the global QS regulator, RhlR (down-regulated in our PF-treated culture by 1.25 fold), committed a metabolic suicide by overproduction of anaerobic NO [38]. Genes involved in denitrification can be expressed even in absence of added nitrate or nitrite [40]. As expression of the enzyme (nitrite reductase) leading to the formation of NO was not shown to be affected in our transcriptome data, we can hypothesize that $P$. aeruginosa's ability to detoxify NO is compromised under the influence of PF. During our experiments, the test bacterium was incubated under aerobic conditions (without continuous agitation). Denitrification has been observed to occur in presence of oxygen (at dissolved oxygen levels of $1-1.3 \mathrm{mg} / \mathrm{L}$ ), in many microbial strains including $P$. aeruginosa [41]. Looking at the gene expression profile, it can be said that PF affected nitrogen metabolism in P. aeruginosa. Among the genes associated with nitrogen metabolism napB and narH were respectively up-regulated (5.26 fold) and down-regulated (2.34 fold).
Biofilm formation in many bacteria may be regulated by the signaling molecule NO. Some reports in literature describe an effect of $\mathrm{NO}$ on bacterial biofilm formation [42-45]. Endogenously generated NO can have an important role in biofilm regulation. Apparently NO seems to have a broad-spectrum anti-biofilm effect. Our experiments indicated that in presence of PF, $P$. aeruginosa biofilm formation was reduced by $26.50 \%$ (Fig. 1c). NO-dependent biofilm regulation in $P$. aeruginosa has been studied extensively. $P$. aeruginosa remain in the biofilm state until exposed to about $0.025-2500 \mathrm{nM} \mathrm{NO}$, at which point they revert to planktonic lifestyle [42]. When exposed to NO concentrations $>\sim 25 \mu \mathrm{M}$, however, biofilm formation was enhanced relative to biofilm formation in the absence of NO. Thus, in P. aeruginosa, nanomolar NO can be said to cause biofilm dispersal. One of the top 10 down-regulated genes in our experimental culture, arsR, was down-regulated by 6 fold, which acts as a transcriptional regulator for ArsR family, a member of which PyeR has been shown to be implicated in regulation of biofilm formation [46].

Response of $P$. aeruginosa to $\mathrm{NO}$ is linked to its denitrification abilities. A NO reductase (which was down-regulated in our PF-exposed culture) mutant ( $\triangle$ norCB) exhibits greatly enhanced dispersal [42]. In $P$. aeruginosa, redox signalling regulates the denitrification pathway through a cascade of transcription factors. The 
global oxygen-sensing regulator ANR (anaerobic regulation of arginine deaminase and nitrate reduction) and DNR (dissimilatory nitrate respiration regulator) regulate a network of genes needed to respond to low oxygen tension and the presence of nitrate, nitrite, and other $\mathrm{N}$-oxides [47-49]. DNR, a member of the FNR family, has been demonstrated to be a heme protein capable of binding NO [50]. In PF-treated culture, DNR was down-regulated by 1.62 fold. Exposure to NO is associated with regulation of intracellular levels of c-di-GMP through the interaction of many diguanylate cyclases (up-regulated by 4.21 fold in PF-treated culture) and phosphodiesterases (down-regulated 1.76 fold in PF-treated culture) [51]. c-di-GMP is a secondary messenger molecule recognized as a key bacterial regulator of multiple processes such as virulence, differentiation, and biofilm formation. Cellular levels of c-di-GMP are modulated by the opposing activities of diguanylate cyclases (DGCs) and phosphodiesterases (PDEs) synthesizing and degrading c-di-GMP, respectively [52]. A chemotaxis transducer $B d l A$ has been implicated in c-di-GMP degradation and biofilm dispersal upon NO detection [53, 54]. BdlA appears to also respond to many environmental cues in addition to NO. $b d l A$ was down-regulated by 1.28 fold under the influence of PF, which might have caused a reduction in the bacteria's ability to respond to external environmental changes, and also that for chemotaxis. Amongst the chemotaxis associated genes, four (PA4290, PA0175, PA0179, PA0177) were significantly differentially expressed. From the gene expression data, it seems that ability of the PF-treated bacterium to detoxify NO is compromised, whereas such detoxification activity (e.g. NOR) has been reported to be important for virulence expression of this pathogen towards the silkworm Bombyx mori [39].

Amongst the significantly down-regulated genes in the PF-treated $P$. aeruginosa, ten were related to secretion systems. Of these, three (PA1702, pscL, pscT) were type III secretion system (T3SS) proteins, which are considered as major virulence determinants manipulating eukaryotic host cell responses [55]. Since these proteins are present in a broad range of pathogens, the polyherbal formulation studied by us can be expected to exert a broad-spectrum anti-virulence effect. Earlier we have shown this formulation to be active against multiple gram-positive and gram-negative pathogens viz. Staphylococcus aureus, Chromobacterium violaceum, and Serratia marcescens [17]. Amongst the significantly up-regulated genes, there were 11 secretion-associated proteins, of which one belonged to T3SS, and six were that of Type 6 secretion system (T6SS). Since the secretion-associated genes including those belonging to T3SS/ T6SS were not exclusive to the list of up-regulated or down-regulated genes, we can not have a straight conclusion regarding whether the effect of PF on secretion machinery of $P$. aeruginosa is inhibitory or stimulatory, but it clearly disturbs the secretion machinery on a large scale, as the total number of secretion-associated genes expressed differentially in the PF-treated culture reached 21 (including 2 of T2SS, 4 of T3SS, and 9 of T6SS). T3SS is an important virulence factor of $P$. aeruginosa, shared with many other gram-negative bacteria. It is a hollow molecular needle that transfers effector toxins directly from the bacterium into the host cell cytosol. This complex macromolecular machine works in a heavily regulated manner and is capable of manipulating the host cell in multiple ways [55]. One of the down-regulated T3SS genes pscL regulates $p s c N$, which is believed to be an ATPase powering the $P$. aeruginosa secretion system [56]. The expression of H1-T6SS genes in P. aeruginosa is controlled by the RetS sensor [57], which was up-regulated by 1.58 fold. It plays a key role in the reciprocal regulation of virulence factors required for acute versus chronic infection and is postulated to act in concert with two other sensor kinase-response regulator hybrids, GacS and LadS. RetS also regulates type IV pilus expression and exopolysaccharide synthesis [58]. One of the T6SS secreted protein $\operatorname{VgrG}$ (PA2373) was down-regulated by 1.63 fold in the PF-exposed culture. VgrG proteins are required for secretion of a genuine H1-T6SS substrate, Tse3, which is one of the seven toxins fired by H1-T6SS. VgrG proteins are not only secreted components but are essential for secretion of other T6SS substrates [57]. Out of the total nine T6SS genes expressed differentially, 6 were up-regulated. The T6SS machinery has been indicated to be expressed upon addition of antimicrobial substances, without the secretion activity necessarily being active. Bacteria may sense presence of antimicrobial substances in their environment, and mount an appropriate self-defense response against them. The T6SS might be one of these defense mechanisms [59]. Hence, the up-regulation of multiple T6SS genes in the PF-exposed culture can be interpreted as one of the defensive responses activated by the bacteria against some of the PF ingredients. However, at the same time, 3 of the down-regulated T6SS genes indicates that in presence of PF, the defensive response of bacteria was not allowed to express fully.

Among the top 20 up-regulated genes, three $(\operatorname{mex} C$, oprJ, and mexD) were efflux system associated proteins, over-expressed with the fold change values ranging from 4.16 to 16.83 . mex $C D$-oprJ is an envelope stress-inducible multidrug efflux operon of $P$. aeruginosa. A gene encoding a homologue of the $N f x B$ repressor (up-regulated by 1.69 fold) of this operon, occurs downstream of oprJ, and is believed to act as a second repressor of this efflux operon. Expression of PA4596 (up-regulated by 2.50 fold) gets induced under conditions of envelope stress, and thus PF can be said to be capable of putting the susceptible 
bacterium under envelope stress. MexCD-OprJ is an antibiotic efflux system in P. aeruginosa, whose expression is governed by stress, e.g. envelope stress caused by membrane-damaging agents like detergents, organic solvents, hydrocarbons and biocides. This tripartite efflux system accommodates multiple classes of antimicrobials, including clinically relevant antibiotics, and biocides like triclosan and chlorhexidine, and so, its expression promotes multidrug resistance in this organism [60]. However, in our study $P$. aeruginosa failed to develop resistance to PF, even after repeated subculturing on PF-containing medium. Overexpression of MexCD-OprJ was shown to reduce $P$. aeruginosa virulence by promoting its susceptibility to complement-mediated killing [61].

The third top up-regulated (by 10 fold) gene (PA3441/ $s s u F$ ) in PF-treated $P$. aeruginosa was a probable molybdopterin-binding protein. In this culture, $\bmod A$ (molybdenum ABC transporter) was found to be down-regulated by 1.59 fold, which is a molybdate transport system permease protein involved in molybldanum homeostasis. In total, 7 genes associated with molybdenum homeostasis were differentially expressed in the PF-treated culture, of which 5 were up-regulated and 2 were down-regulated. Molybdenum homeostasis is required for nitrate utilization, biofilm formation, and virulence expression in P. aeruginosa [62]. Nitrate reduction in $P$. aeruginosa is dependent on the availability of oxyanionic form of molybdenum. Down-regulation of $\bmod A$ may be a strategy of $P$. aeruginosa to avoid the NO toxicity, as its down-regulation can reduce the cellular molybdate concentrations culminating into an inhibitory effect on nitrate reduction. It can be concluded that under the influence of PF molybdanum homeostasis is disturbed in $P$. aeruginosa, with nitrate reduction being permitted. Conditions that permit nitrate reduction cause inhibition of biofilm formation and alteration in fatty acid composition of $P$. aeruginosa. Disturbance of the molybdenum homeostasis in PF-treated culture can be well corroborated with reduced biofilm formation, altered nitrate reduction, and up-regulation of the genes believed to be involved in responding to the envelope stress, as molybdenum homeostasis has been documented in literature to be important for nitrate reduction, biofilm formation, and cell membrane composition [63].

Among other genes associated with molybdenum homeostasis and/ or cellular processes affected by it, expressed differentially were narH ( -2.34 fold), nirS (2.78 fold), norC (-5.04 fold), norB (-5.44 fold), napA (-1.34 fold), and napB (5.26 fold). narH, nirS, norCB are all enzymatic complexes involved in the major dissimilarly nitrate reduction pathway, whereas NapAB codes for a periplasmic nitrate reductase complex. Enzymes of the dissimilatory nitrate reductase pathway require a transition metal cofactor (iron/ copper/ molybdenum) for their activity [63].

Among the differentially expressed genes a good number (33 down-regulated; 22 up-regulated) were those coding for transcriptional regulators. Notable among the down-regulated ones were those (10 in number) part of the family LysR, which regulate transcription of the genes associated with MexEF-OprN efflux system, biofilm formation, virulence, metabolism, QS, and motility. Another gene which can be considered important amongst those affected by PF was pchB (down-regulated by 1.91 fold) coding for isochorismate pyruvate lyase. This enzyme is involved in the transformation of isochorismate to pyruvate and salicylate, which is the committed step in biosynthesis of salicylate-based siderophores in many pathogenic bacteria. This is one of the many enzymes involved in synthesis of phenazines and siderophores from chorismate, and being absent from mammals, it can be viewed as a potential target for novel antimicrobials [64].

After having a generalized consideration of the differently expressed genes, we focused particularly on the genes associated with traits assayed by us during in vitro experiments. Pyocyanin is among the most infamous virulence factors of $P$. aeruginosa, whose production was reduced by nearly $14 \%$ under the influence of PF. $P$. aeruginosa synthesizes pyocyanin from chorismate through a pathway mediated by phzABCDEFG operon. $p h z H$ and $p h z M$, though just marginally missed passing our cut-off value of 1.5 fold differential expression, their fold change values $(-1.49$ and -1.41 respectively) were statistically significant at $p<0.05$. Both of these are pyocyanin (phenazine) biosynthetic proteins $[65,66]$. Pyocyanin is a blue redox-active extracellular phenazine pigment [32], which is produced in response to PQS signalling [67], and acts as a terminal signalling factor in the QS network of $P$. aeruginosa [68]. PQS biosynthesis requires conversion of the central metabolite chorismate to anthranilate by anthranilate synthase. This reaction is also the first step in tryptophan biosynthesis. P. aeruginosa possesses two functionally non-redundant anthranilate synthases, TrpEG and PhnAB, of which the latter was down-regulated by 1.32 fold. $k y n B$ of the kynurenine pathway, which is linked to $P$. aeruginosa virulence as tryptophan is incorporated into the Pseudomonas quinolone signal (PQS) through this pathway, was down-regulated by 3.15 fold. The kynurenine pathway is the main source of anthranilate for PQS production when P. aeruginosa is grown in the presence of tryptophan or tryptophan breakdown metabolites [69].

In vitro PF-treated $P$. aeruginosa produced nearly $37 \%$ higher pyoverdine. Pyoverdine, a siderophore, is an important virulence factor for $P$. aeruginosa that helps bacteria to survive in iron-limiting conditions [70]. 
Genes associated with pyoverdine biosynthesis, maturation and transport, $p v d A$ (1.28 fold), $p v d F$ (1.36 fold), $p v d G$ (1.27 fold), $p v d H$ (1.24 fold), $p v d P$ (1.38 fold), $p v d Q$ (1.21 fold), $p v d R$ (1.34 fold), were up-regulated significantly, though could not cross the cut-off value of 1.5 fold. $P$. aeruginosa has been reported to produce pyoverdine upon exposure to oxidative stress agent. In general, factors stimulating production of siderophores may be postulated to raise the susceptibility of microorganisms to oxidative damage [71]. Gene expression profile indicates that PF can be believed to be capable of inducing oxidative stress in $P$. aeruginosa, as in total 11 genes involved in oxidative stress response were up-regulated in the PF-treated culture. Of which, two were those coding for catalase i.e. katA (1.85 fold) and katN (1.67 fold), which is a well-known anti-oxidant enzyme, though the in vitro catalase activity enhancement was smaller (2.14\%), albeit statistically significant. Other oxidative stress response genes (PA4172, ospR, PA2580, PA0848, ahpC, PA3534, PA2826, nuoK, katA, katN, PA1266) were upregulated with a fold-change value ranging from 1.62 to 3.93. On the other hand, seven (nosL, nuoI, PA3450, PA0942, PA1192, yrfI, PA3180) of the oxidative response genes were down-regulated with fold change values ranging from 1.52 to 4.16 which may mean that organism failed to activate its oxidative stress response machinery fully in presence of PF. Oxidative stress stems from generation of the reactive oxygen species (ROS), and potentiation of ROS in disease conditions using small molecules has been considered as drug design strategy for new drug development, since ROS generators may act as effective modulators of virulence [72]. ROS can be generated by destabilization of the iron-sulfur clusters [73], and in our experimental culture, three Fe-S proteins (PA0665, PA1881, PA0185) were differentially expressed passing the dual criteria of $p \leq 0.05$ and fold-change value $\geq 1.5$.

From the hitherto description, we can say that PF makes $P$. aeruginosa face iron starvation and oxidative stress. Here enhanced pyoverdine production seems more likely to be due to oxidative stress, as gene $p c h B$ coding for isochorismate pyruvate lyase, involved in the conversion of isochorismate into pyruvate and salicylate siderophore, was down-regulated by 1.91 fold, which is likely to lessen the pyochelin mediated iron acquisition in $P$. aeruginosa. Fur, the key regulator of iron metabolism that regulates the expression of iron acquisition and storage systems in response to intracellular iron [74], was down-regulated by 1.16 fold $(p<0.00003)$. It has roles in numerous other aspects of physiology, too. One of the ways, many pathogenic strains employ to fulfil their iron requirement is to source it from the blood cells after hemolysing them. Interestingly, hemolytic potential of this pathogen suffered a $\sim 16 \%$ downfall owing to PF-treatment. PA3402 coding for a haemolysin secretory protein belonging to the HlyD family was down-regulated by 1.58 fold. Heme contributes to iron-homeostasis in bacteria, which is important for virulence gene expression [75]. Maintenance of ironhomeostasis is an integral part of the metabolism because imbalance in iron metabolism results in ROS generation, which is harmful for the organism [76]. In our experimental culture, genes required for heme biosynthesis nirS and heme lyase $\mathrm{ccmH}$ were down-regulated respectively by 2.78 , and 1.94 fold. bphO encoding heme oxygenase was down-regulated by 1.76 fold, PA5328 encoding mono-heme cytochrome $\mathrm{c}$ was up-regulated by 8 fold, and PA1478 encoding heme-exporter by 3.57 fold. Genes encoding heme acquisition, hasD and hasR were up-regulated by 2.45 and 1.62 fold respectively. PA4357 coding for ferrous iron transport protein C (2.06 fold), PA0665 encoding iron-sulfur cluster insertion protein (2.05 fold), exbD1 encoding biopolymer transport protein TolR (2.04 fold), iron-enterobactin transferase (1.76 fold), and PA0192 for iron complex outer membrane receptor protein $(1.66$ fold) were all down-regulated.

In vitro biofilm formation was inhibited by nearly $25 \%$, when $P$. aeruginosa was challenged with PF $(750 \mu \mathrm{g} / \mathrm{mL})$. Many of the biofilm/polysaccharide synthesis associated genes were differentially expressed in the PF-treated culture. Notable among them are hutU (2.46 fold), and $p s l K$ ( 2.44 fold). Former is a urocanate hydratase catalyzing histidine degradation, mutation in which is reported to result in reduced biofilm formation [77]. Latter is a polysaccharide biosynthesis protein. Up-regulation of these genes may be a part of $P$. aeruginosa's response to counteract reduced biofilm formation forced by PF. PA1021 coding for enoyl-CoA hydratase, required for synthesis of the biofilm dispersion autoinducer cis-2-decenoic acid was significantly up-regulated (2.88 fold). Among the relevant down-regulated genes were: flagellar assembly proteins flgE (1.55 fold) and fliE (1.53 fold), twitching motility protein pilU (1.52 fold), pili biogenesis protein pilC (1.59 fold), type IV pili assembly protein pilE (2.62 fold), lipopolysaccharide biosynthesis proteins PA4819 coding for polyisoprenyl-phosphate glycosyltransferase (2.30 fold) and PA3430 coding for aldolase (1.61 fold), lipopolysaccharide export system protein LptA (1.5 fold), alginate biosynthesis proteins algE (3.0 fold) and alg8 (1.52 fold). In context of the down-regulated flagellar/ twitching motility proteins, it should be noted that flagellar and twitching motility have been shown to be necessary for $P$. aeruginosa biofilm development [78].

This study has employed the nematode worm $C$. elegans as the model host for demonstrating the in vivo anti-infective potential of PF. Cezairliyan et al. [79] 
identified three phenazine class molecules (1-hydroxyphenazine, phenazine-1-carboxylic acid, and pyocyanin) capable of killing nematodes. In our PF-exposed culture, 3 genes phzC1 (1.97 fold), pchB (-1.91 fold), PA5357 (1.89 fold) associated with phenazine synthesis were differentially expressed with fold-change values $\geq 1.5$. From among the $P$. aeruginosa PA14 virulence-attenuated genes identified in the $C$. elegans infection model by Feinbaum et al. [80], 7 [PA0745 (1.75 fold), PA0215 liuA (1.84 fold), lasI (1.57 fold), PA1766 (1.58), PA1665 (fha2) (1.95 fold), $p h z C 1$ (1.97), $p h z H$ (- 1.49 fold)] were differently expressed in our PF-treated culture.

Here, we have shown different traits of $P$. aeruginosa such as pyocyanin and pyoverdine production, hemolytic ability, and biofilm formation getting affected by the test formulation. All these traits, and upto a notable extent virulence too, are controlled by QS [33, 81]. A brief description of the differently expressed QS-associated genes follows. Five of the genes (PA1827, PA0182, fabI, PA1470, PA5071) involved in the production of the autoinducer 3-oxo- $\mathrm{C}_{12}$ - $\mathrm{HSL} / \mathrm{C}_{4}$ - $\mathrm{HSL}$ were down-regulated in the range of 2.02-4.52 fold. These two acylhomoserine lactones are the major components of las and rhl systems respectively [82]. PA1827 ( $f a b G)$, down-regulated by 4.52 fold, has a key role in the bacterial fatty acid synthesis II system in pathogenic microorganisms, which has been viewed as an attractive drug target, since fatty acid synthesis is a primary metabolic pathway, and a wide range of cellular processes are dependent on fatty acids [83]. In PF-treated culture, as total of 16 (of which 12 down- regulated) genes associated with acyl-carrier proteins and/ or fatty acid metabolism were differentially expressed. QS negative regulator $R s a L$, which has been reported to bind to the lasI promoter was down-regulated in our study by 1.50 fold, and this can explain the up-regulation of the lasI to almost identical extent (by 1.57 fold). P. aeruginosa QS system is connected with other cellular global regulatory networks in a complicated manner, as it is regulated by multiple regulatory factors. Of these many regulatory factors, one is the above mentioned RsaL. PA4790 coding for S-adenosylmethionine-dependent methyltransferase involved in production of AI-2, was up-regulated by 2.25 fold. Meijler [84] refers QS as the 'collective nose' of bacteria to "smell out" environmental conditions and communicate among themselves, which helps them optimize their virulence response. Differences in environmental conditions such as phosphate and iron availability can significantly influence the activation of the different QS systems [85-87], and that seems to be the case with our PF-exposed culture. Nutrients like iron and phosphate can directly influence the activities of the various QS systems and resultant outcomes on the secretion of virulence factors such as pyocyanin. Quite a few genes in the PF-challenged $P$. aeruginosa, associated with phosphate acquisition/ transport/metabolism viz. PA3383 (6.33 fold $\uparrow$ ), PA2548 (1.55 fold $\uparrow$ ), PA3377 (3.45 fold $\downarrow$ ), and PA0450 (1.60 fold $\downarrow$ ) were differentially expressed.

We tried to see whether any notable overlap can be detected among the genes expressed differentially upon PF-treatment, with those reported in $P$. aeruginosa

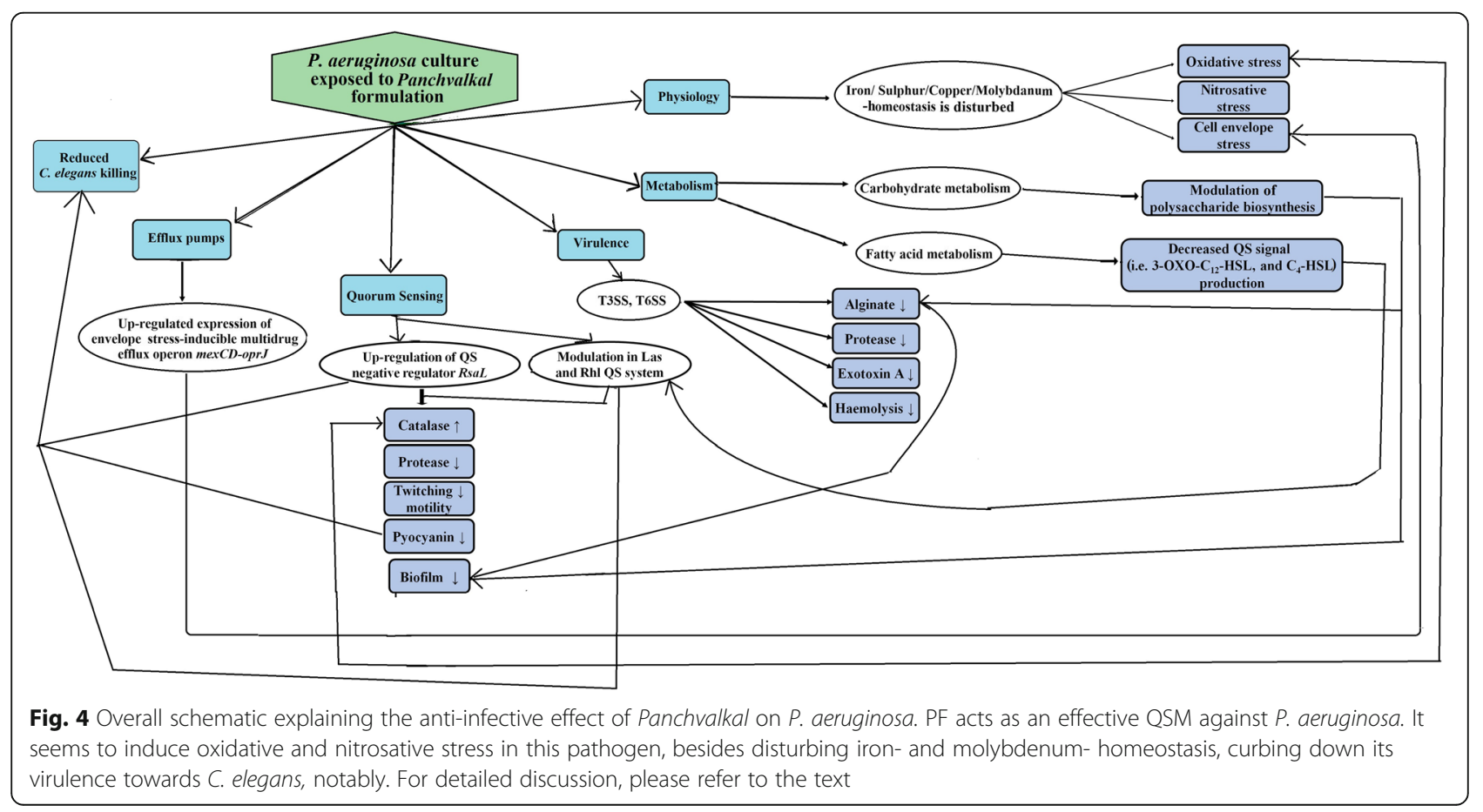


challenged with other natural products. Such a comparison with the transcriptome of 6-gingerol-treated- P. aeruginosa revealed that 96 of the genes reported by them [6] to be differentially expressed, matches with our list of such genes. Little overlap was there with reports describing effect of furanone C-30 [88] or curcumin [32] on $P$. aeruginosa genes/ proteins; number of matching entities being only 4 (PA1665, PA1662, PA1668, chiC) and 9 respectively. This however is not surprising, as polyherbal formulations like one used in our study are likely to have more intracellular targets, as against any single molecule.

\section{Conclusion}

This study has generated scientific evidence regarding anti-infective potential of the polyherbal Panchvalkal preparation, validating its therapeutic use prescribed in ayurved. Here we could demonstrate efficacy of $\mathrm{PF}$ against one of the most notorious pathogen $P$. aeruginosa, in vitro as well as in vivo. Any polyherbal formulation is very much likely to have multiple targets inside the susceptible pathogenic bacteria, and this was observed with Panchvalkal too, as it could significantly alter the expression of 787 ( $14 \%$ of the genome) genes in the test pathogen. To the best of our awareness, this is the first report describing effect of Panchvalkal formulation on gene expression of any bacterial pathogen at the whole transcriptome level. The major mechanisms through which PF seems to exert its anti-virulence effect on $P$. aeruginosa (Fig. 4) are by generating oxidative and nitrosative stress, by disturbing the molybdenum- and iron- homeostasis, and by interfering with QS. Since PF exerted its anti-virulence effect without any significant effect on bacterial growth, it can be said not to put a strong selection pressure on this bacterium for resistance development. Even multiple subculturings of this bacterium on PF containing media did not induce resistance, as described in our results of present study. This research report is a good demonstration of the therapeutic utility of the 'polyherbalism' concept, so common in ayurved, and also of how effective the modern 'omics' tools are in validating the traditional medicine i.e. ayuromics. Specifically tailored cocktails of virulence modulators are likely to be more effective solutions in vivo than single agent treatments.

\section{Additional file}

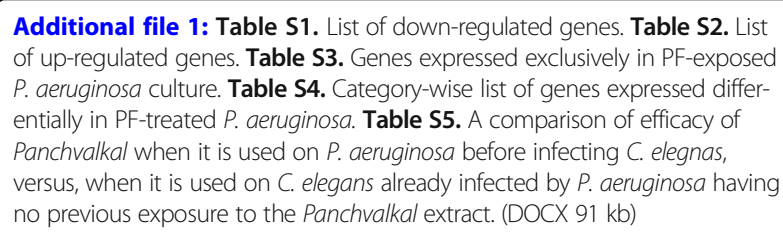

\section{Abbreviations}

PF: Panchvalkal formulation; QS: Quorum Sensing; QSM: Quorum sensing modulatory

\section{Acknowledgements \\ Authors thank Nirma Education and Research Foundation (NERF) for financial and infrastructural support.}

\section{Funding}

No extramural funds availed.

\section{Availability of data and materials}

All the raw sequence data has been submitted to Sequence Read Archive. Relevant accession no. are SRX2855033 and SRX2855034.

\section{Authors' contributions}

HP conceptualized the study and made the test formulation available for the study. VK contributed towards designing the experiments, data analysis, and manuscript writing. CJ and PP executed the experiments in lab, participated in literature survey, data analysis, and manuscript formatting. All authors read and approved the final manuscript.

\section{Authors' information}

CJ and PP are currently pursuing Ph.D. at Institute of Science, Nirma University, under supervision of VK. VK is a microbiologist interested in anti-infective plant products, and microwave biology. Besides working on bioactive natural products, this group is also engaged in deciphering the molecular basis of bacterial response to sonic stimulation. HP is trained both in ayurved, as well as modern medicine, and is zealous about scientific validation of traditional Indian medicine, at Dr. Palep's Medical Research Foundation, Mumbai.

Ethics approval and consent to participate

This study received Ethical Approval from the Institutional Ethics Committee (IEC) for the use of the investigator's/students' blood. All concerned provided written informed consent for their blood to be used.

\section{Consent for publication}

All authors agree for this publication.

\section{Competing interests}

The authors declare that they have no competing interests.

\section{Publisher's Note}

Springer Nature remains neutral with regard to jurisdictional claims in published maps and institutional affiliations.

\section{Author details}

${ }^{1}$ Institute of Science, Nirma University, Ahmedabad 382481, India. ${ }^{2}$ Dr. Palep's Medical Research Foundation, Mumbai, India.

Received: 8 January 2018 Accepted: 2 January 2019

Published online: 17 January 2019

\section{References}

1. Choi JY, Sifri CD, Goumnerov BC, Rahme LG, Ausubel FM, Calderwood SB. Identification of virulence genes in a pathogenic strain of Pseudomonas aeruginosa by representational difference analysis. J Bacteriol. 2002;184(4): 952-61.

2. Lee J, Zhang $\mathrm{L}$. The hierarchy quorum sensing network in Pseudomonas aeruginosa. Protein Cell. 2015;6(1):26-41.

3. Moore LS, Cunningham J, Donaldson H. A clinical approach to managing Pseudomonas aeruginosa infections. Br J Hosp Med. 2016;77(4):C50-4.

4. Global priority list of antibiotic-resistant bacteria to guide research, discovery, and development of new antibiotics. World Health Organization Report. 2017; http://www.who.int/medicines/publications/global-priority-listantibiotic-resistant-bacteria/en/.

5. Davenport PW, Griffin JL, Welch M. Quorum sensing is accompanied by global metabolic changes in the opportunistic human pathogen Pseudomonas aeruginosa. J Bacteriol. 2015;197(12):2072-82. 
6. Kim HS, Lee SH, Byun Y, Park HD. 6-Gingerol reduces Pseudomonas aeruginosa biofilm formation and virulence via quorum sensing inhibition. Sci rep. 2015;5. doi:org/https://doi.org/10.1038/srep08656.

7. Zhu H, Sun SJ. Inhibition of bacterial quorum sensing-regulated behaviors by Tremella fuciformis extract. Curr Microbiol. 2008;57(5):418-22.

8. Vandeputte OM, Kiendrebeogo M, Rajaonson S, Diallo B, Mol A, El Jaziri M, Baucher M. Identification of catechin as one of the flavonoids from Combretum albiflorum bark extract that reduces the production of quorumsensing-controlled virulence factors in Pseudomonas aeruginosa PAO1. Appl Environ Microbiol. 2010;76(1):243-53.

9. Zaki AA, Shaaban MI, Hashish NE, Amer MA, Lahloub MF. Assessment of anti-quorum sensing activity for some ornamental and medicinal plants native to Egypt. Sci Pharm. 2012;81(1):251-8.

10. Chenia HY. Anti-quorum sensing potential of crude Kigelia africana fruit extracts. Sensors. 2013:13(3):2802-17.

11. Norizan SN, Yin WF, Chan KG. Caffeine as a potential quorum sensing inhibitor. Sensors. 2013;13(4):5117-29.

12. Husain FM, Ahmad I, Khan MS, Ahmad E, Tahseen Q, Khan MS, Alshabib NA. Sub-MICs of Mentha piperita essential oil and menthol inhibits AHL mediated quorum sensing and biofilm of gram-negative bacteria. Front Microbiol. 2015. https://doi.org/10.3389/fmicb.2015.00420

13. Parasuraman S, Thing GS, Dhanaraj SA. Polyherbal formulation: concept of ayurveda. Pharmacogn Rev. 2014;8(16):73-80.

14. Joshi J, Rege V, Bhat R, Vaidya R, Joshi B, Nadkarni D, Pandita N, Sunder S, Rastogi N, Vaidya A. Use of cervical cytology, vaginal pH and colposcopy as adjuncts to clinical evaluation of Ayurvedic vaginal douche, Panchavalkal, in leucorrhoea. J Cytol. 2004:21:33-8.

15. Raut AA, Chorghade MS, Vaidya ADB. Reverse pharmacology. Innov Approaches Drug Discov. 2017. https://doi.org/10.1016/B978-0-12-801814-9.00004-0.

16. Khadkutkar DK, Kanthi VG. Therapeutic uses of panchvalkal in different forms-A review. Ayurlog Natl J Res Ayurveda Sci. 2014;2:1-5.

17. Patel P, Joshi C, Palep H, Kothari V. Anti-infective potential of a quorum modulatory polyherbal extract (Panchvalkal) against certain pathogenic bacteria. bioRxiv. 2017; doi: https://doi.org/10.1101/172056

18. Chaudhari V, Gosai H, Raval S, Kothari V. Effect of certain natural products and organic solvents on quorum sensing in Chromobacterium violaceum. Asian Pac J Trop Med. 2014;7:S204-11.

19. Joshi C, Kothari V, Patel P. Importance of selecting appropriate wavelength, while quantifying growth and production of quorum sensing regulated pigments in bacteria. Recent Pat Biotechnol. 2016;10(2):145-52.

20. El-Fouly MZ, Sharaf AM, Shahin AM, El-Bialy HA, Omara AMA. Biosynthesis of pyocyanin pigment by Pseudomonas aeruginosa. J Radiat Res App Sci. 2015; 8(1):36-48.

21. Unni K, Priji P, Geoffroy V, Doble M, Benjamin S. Pseudomonas aeruginosa BUP2-A novel strain isolated from malabari goat produces type 2 pyoverdine. Adv Biosci Biotechnol. 2014;5(11):874-85.

22. Neun BW, llinskaya AN, Dobrovolskaia MA. Analysis of hemolytic properties of nanoparticles. NCL method ITA-1 version 1.2, nanotechnology characterization laboratory, Frederick, MD. https://ncl.cancer.gov/sites/ default/files/protocols/NCL_Method_ITA-1.pdf. Accessed 20 July 2016.

23. Ferro TA, Araujo JM, dos Santos Pinto BL, dos Santos JS, Souza EB, da Silva BL, Colares VL, Novais TM, MB Filho C, Struve C, Calixto JB, Monteiro-Neto V, da Silva LC, Fernandes ES. Cinnamaldehyde inhibits Staphylococcus aureus virulence factors and protects against infection in a Galleria mellonella model. Front Microbio. 2016;7. https://doi.org/10.3389/fmicb.2016.02052.

24. Iwase T, Tajima A, Sugimoto S, Okuda KI, Hironaka I, Kamata Y, Takada K, Mizunoe Y. A simple assay for measuring catalase activity: a visual approach. Sci Rep. 2013;3:3081.

25. Weydert CJ, Cullen JJ. Measurement of superoxide dismutase, catalase and glutathione peroxidase in cultured cells and tissue. Nat Protoc. 2009;5(1):51-66.

26. Patel I, Patel V, Thakkar A, Kothari V. Tamarindus indica (Cesalpiniaceae), and Syzygium cumini (Myrtaceae) seed extracts can kill multidrug resistant Streptococcus mutans in biofilm. J Nat Remed. 2013;13(2):81-94.

27. Trafny EA, Lewandowski R, Zawistowska-Marciniak I, Stępińska M. Use of MTT assay for determination of the biofilm formation capacity of microorganisms in metalworking fluids. World J Microbiol Biotechnol. 2013; 29(9):1635-43

28. Eng SA, Nathan S. Curcumin rescues Caenorhabditis elegans from a Burkholderia pseudomallei infection. Front Microbiol. 2015;6:Article 290.

29. Defoirdt T, Brackman G, Coenye T. Quorum sensing inhibitors: how strong is the evidence? Trends Microbiol. 2013;21(12):619-24.
30. Cornelis P. Iron transport systems and iron homeostasis in Pseudomonas. In: Chakraborty R, Braun V, Hantke K, Cornelis P, editors. Iron uptake in bacteria with emphasis on E. coli and Pseudomonas. Netherlands: Springer Briefs in Molecular Science. Springer; 2013. p. 67-89.

31. Hall S, McDermott C, Anoopkumar-Dukie S, McFarland AJ, Forbes A, Perkins AV, Davey AK, Chess-Williams R, Kiefel MJ, Arora D, Grant GD. Cellular effects of pyocyanin, a secreted virulence factor of Pseudomonas aeruginosa. Toxins. 2016;8(8):236. https://doi.org/10.3390/toxins8080236.

32. Sethupathy S, Prasath KG, Ananthi S, Mahalingam S, Balan SY, Pandian SK. Proteomic analysis reveals modulation of iron homeostasis and oxidative stress response in Pseudomonas aeruginosa PAO1 by curcumin inhibiting quorum sensing regulated virulence factors and biofilm production. J Proteome. 2016:145:112-26.

33. Attila C. Identification of Pseudomonas aeruginosa virulence factors via a poplar tree model. Ph. D. Dissertation. Texas A\&M University. 2008. http:// oaktrust.library.tamu.edu/bitstream/handle/1969.1/ETD-TAMU-2326/ATTILADISSERTATION.pdf.

34. Wojnicz D, Korzekwa K, Cisowska A. Bactericidal action of human serum against Pseudomonas aeruginosa strains with hydrophilic or hydrophobic cell surface. Med Dosw Mikrobiol. 2008;60(4):303-9.

35. Muschel LH, Ahl LA, Fisher MW. Sensitivity of Pseudomonas aeruginosa to normal serum and to polymyxin. J Bacteriol. 1969;98(2):453-7.

36. Palep H, Kothari V, Patil S. Quorum sensing inhibition: A new antimicrobial mechanism of Panchvalkal, an ayurvedic formulation. Bombay Hosp J. 2016; 58(2):198-204.

37. Kyoto Encyclopedia of Genes and Genomes (KEGG). http://www.genome.jp/ dbget-bin/get_linkdb?-t+genes+gn:T00035. Accessed 5 June 2017.

38. Yoon SS, Karabulut AC, Lipscomb JD, Hennigan RF, Lymar SV, Groce SL, Herr AB, Howell ML, Kiley PJ, Schurr MJ, Gaston B. Two-pronged survival strategy for the major cystic fibrosis pathogen, Pseudomonas aeruginosa, lacking the capacity to degrade nitric oxide during anaerobic respiration. EMBO J. 2007; 26(15):3662-72

39. Arai $\mathrm{H}$, liyama $\mathrm{K}$. Role of nitric oxide-detoxifying enzymes in the virulence of Pseudomonas aeruginosa against the silkworm, Bombyx mori. Biosci Biotechnol Biochem. 2013;77(1):198-200.

40. Hammond JH, Dolben EF, Smith TJ, Bhuju S, Hogan DA. Links between Anr and quorum sensing in Pseudomonas aeruginosa biofilms. J Bacteriol. 2015; 197:2810-20

41. Chen F, Xia Q, Ju LK. Aerobic denitrification of Pseudomonas aeruginosa monitored by online NAD(P)H fluorescence. Appl Environ Microbiol. 2003; 69(11):6715-22.

42. Barraud N, Hassett DJ, Hwang SH, Rice SA, Kjelleberg S, Webb JS. Involvement of nitric oxide in biofilm dispersal of Pseudomonas aeruginosa. J Bacteriol. 2006;188(21):7344-53.

43. Plate L, Marletta MA. Nitric oxide modulates bacterial biofilm formation through a multicomponent cyclic-di-GMP signaling network. Mol Cell. 2012; 46(4):449-60.

44. Arora DP, Hossain $S, X u Y$, Boon EM. Nitric oxide regulation of bacterial biofilms. Biochemist. 2015;54(24):3717-28.

45. Cutruzzolà F, Frankenberg-Dinkel N. Origin and impact of nitric oxide in Pseudomonas aeruginosa biofilms. J Bacteriol. 2016;198(1):55-65.

46. Tata M, Wolfinger MT, Amman F, Roschanski N, Dötsch A, Sonnleitner E, Häussler S, Bläsi U. RNASeq based transcriptional profiling of Pseudomonas aeruginosa PA14 after short-and long-term anoxic cultivation in synthetic cystic fibrosis sputum medium. PLoS One. 2016;11(1):e0147811.

47. Schreiber K, Krieger R, Benkert B, Eschbach M, Arai H, Schobert M, Jahn D. The anaerobic regulatory network required for Pseudomonas aeruginosa nitrate respiration. J Bacteriol. 2007;189(11):4310-4.

48. Castiglione N, Rinaldo S, Giardina G, Cutruzzola F. The transcription factor DNR from Pseudomonas aeruginosa specifically requires nitric oxide and haem for the activation of a target promoter in Escherichia coli. Microbiol. 2009;155(9):2838-44.

49. Trunk K, Benkert B, Quack N, Munch R, Scheer M, Garbe J, Jansch L, Trost M, Wehland J, Buer J, Jahn M, Schobert M, Jahn D. Anaerobic adaptation in Pseudomonas aeruginosa: definition of the Anr and Dnr regulons. Environ Microbiol. 2010;12:1719-33.

50. Giardina G, Rinaldo S, Johnson KA, Di Matteo A, Brunori M, Cutruzzolà F. NO sensing in Pseudomonas aeruginosa: structure of the transcriptional regulator DNR. J Mol Biol. 2008;378(5):1002-15.

51. Barraud N, Schleheck D, Klebensberger J, Webb JS, Hassett DJ, Rice SA, Kjelleberg S. Nitric oxide signaling in Pseudomonas aeruginosa biofilms 
mediates phosphodiesterase activity, decreased cyclic di-GMP levels, and enhanced dispersal. J Bacteriol. 2009;191(23):7333-42.

52. Petrova OE, Cherny KE, Sauer K. The Pseudomonas aeruginosa diguanylate cyclase GcbA, a homolog of $P$. fluorescens GcbA, promotes initial attachment to surfaces, but not biofilm formation, via regulation of motility. J Bacteriol. 2014;196(15):2827-41.

53. Barraud N, Storey MV, Moore ZP, Webb JS, Rice SA, Kjelleberg S. Nitric oxidemediated dispersal in single-and multi-species biofilms of clinically and industrially relevant microorganisms. Microb Biotechnol. 2009;2(3):370-8.

54. Morgan R, Kohn S, Hwang S-H, Hassett DJ, Sauer K. BdIA, a chemotaxis regulator essential for biofilm dispersion in Pseudomonas aeruginosa. $J$ Bacteriol. 2006;188:7335-43.

55. Galle M, Carpentier I, Beyaert R. Structure and function of the type III secretion system of Pseudomonas aeruginosa. Curr Protein Pept Sci. 2012; 13(8):831-42.

56. Hauser AR. The type III secretion system of Pseudomonas aeruginosa: infection by injection. Nat Rev Microbiol. 2009;7(9):654-65.

57. Hachani A, Lossi NS, Hamilton A, Jones C, Bleves S, Albesa-Jové D, Filloux A. Type VI secretion system in Pseudomonas aeruginosa secretion and multimerization of VgrG proteins. J Biol Chem. 2011;286(14):12317-27.

58. Laskowski MA, Kazmierczak BI. Mutational analysis of RetS, an unusual sensor kinase-response regulator hybrid required for Pseudomonas aeruginosa virulence. Infect Immun. 2006;74(8):4462-73.

59. Jones C, Allsopp L, Horlick J, Kulasekara H, Filloux A. Subinhibitory concentration of kanamycin induces the Pseudomonas aeruginosa type VI secretion system. PLoS One. 2013;8(11):e81132.

60. Purssell A, Fruci M, Mikalauskas A, Gilmour C, Poole K. EsrC, an envelope stress-regulated repressor of the mexCD-oprJ multidrug efflux operon in Pseudomonas aeruginosa. Environ Microbiol. 2015;17(1):186-98.

61. Martínez-Ramos I, Mulet X, Moyá B, Barbier M, Oliver A, Albertí S. Overexpression of MexCD-OprJ reduces Pseudomonas aeruginosa virulence by increasing its susceptibility to complement-mediated killing. Antimicrob Agents Chemother. 2014;58(4):2426-9.

62. Filiatrault MJ, Tombline G, Wagner VE, Van Alst N, Rumbaugh $K$, Sokol $P$, Schwingel J, Iglewski BH. Pseudomonas aeruginosa PA1006, which plays a role in molybdenum homeostasis, is required for nitrate utilization, biofilm formation, and virulence. PLoS One. 2013;8(2):e55594.

63. Pederick VG, Eijkelkamp BA, Ween MP, Begg SL, Paton JC, McDevitt CA. Acquisition and role of molybdate in Pseudomonas aeruginosa. Appl Environ Microbiol. 2014;80(21):6843-52.

64. DeClue MS, Baldridge KK, Künzler DE, Kast P, Hilvert D. Isochorismate pyruvate lyase: a pericyclic reaction mechanism? J Am Chem Soc. 2005; 127(43):15002-3.

65. Chin-A-Woeng TF, Thomas-Oates JE, Lugtenberg BJ, Bloemberg GV. Introduction of the phzH gene of Pseudomonas chlororaphis PCL1391 extends the range of biocontrol ability of phenazine-1-carboxylic acid-producing Pseudomonas spp. strains. Mol Plant-Microbe Interact. 2001;14(8):1006-15.

66. Parsons JF, Greenhagen BT, Shi K, Calabrese K, Robinson H, Ladner JE. Structural and functional analysis of the pyocyanin biosynthetic protein PhzM from Pseudomonas aeruginosa. Biochemist. 2007;46(7):1821-8.

67. Deziel E, Lepine F, Milot S, He J, Mindrinos MN, Tompkins RG, Rahme LG. Analysis of Pseudomonas aeruginosa 4-hydroxy-2-alkylquinolines (HAQs) reveals a role for 4-hydroxy-2-heptylquinoline in cell-to-cell communication. Proc Natl Acad Sci U S A. 2004;01:1339-44.

68. Dietrich LE, Price-Whelan A, Petersen A, Whiteley M, Newman DK. The phenazine pyocyanin is a terminal signalling factor in the quorum sensing network of Pseudomonas aeruginosa. Mol Microbiol. 2006;61(5):1308-21.

69. Knoten CA, Hudson LL, Coleman JP, Farrow JM, Pesci EC. KynR, a Lrp/AsnCtype transcriptional regulator, directly controls the kynurenine pathway in Pseudomonas aeruginosa. J Bacteriol. 2011 Dec 1;193(23):6567-75.

70. Vinckx T, Matthijs S, Cornelis P. Loss of the oxidative stress regulator OxyR in Pseudomonas aeruginosa PAO1 impairs growth under iron-limited conditions. FEMS Microbiol Lett. 2008;288(2):258-65.

71. Dao KH, Hamer KE, Clark CL, Harshman LG. Pyoverdine production by Pseudomonas aeruginosa exposed to metals or an oxidative stress agent. Ecol Appl. 1999;9(2):441-8

72. Kothari V, Joshi C, Patel P. Alternatives to conventional antimicrobials: Exploring new strategies. In: Bhardwaj AK, editor. Resistance to antibiotics: Are we prepared to handle this growing ghost?. OMICS Group eBooks; 2017.https://www.esciencecentral.org/ebooks/ebookdetail/resistance-toantibiotics-are-we-prepared-to-handle-this-growing-ghost-.
73. Kohanski MA, Dwyer DJ, Hayete B, Lawrence CA, Collins JJ. A common mechanism of cellular death induced by bactericidal antibiotics. Cell. 2007: 130(5):797-810.

74. Escolar L, Perez-Martin J, De Lorenzo V. Opening the iron box: transcriptional metalloregulation by the Fur protein. J Bacteriol. 1999;181:6223-9.

75. Choby JE, Skaar EP. Heme synthesis and acquisition in bacterial pathogens. J Mol Biol. 2016;428(17):3408-28.

76. Bresgen N, Eckl PM. Oxidative stress and the homeodynamics of iron metabolism. Biomol Ther. 2015;5(2):808-47.

77. Lenz M, Retey J. Cloning, expression and mutational analysis of the urocanase gene (hutU) from Pseudomonas putida. FEBS Jl. 1993;217(1):429-34.

78. O'toole GA, Kolter R. Flagellar and twitching motility are necessary for Pseudomonas aeruginosa biofilm development. Mol Microbiol. 1998;30(2): 295-304.

79. Cezairliyan B, Vinayavekhin N, Grenfell-Lee D, Yuen GJ, Saghatelian A, Ausubel FM. Identification of Pseudomonas aeruginosa phenazines that kill Caenorhabditis elegans. PLoS Pathog. 2013;9(1):e1003101. https://doi.org/10. 1371/journal.ppat.100310.

80. Feinbaum RL, Urbach JM, Liberati NT, Djonovic S, Adonizio A, Carvunis AR, Ausubel FM. Genome-wide identification of Pseudomonas aeruginosa virulence-related genes using a Caenorhabditis elegans infection model. PLoS Pathog. 2012;8(7):e1002813. https://doi.org/10.1371/journal.ppat.1002813.

81. Newman JW, Floyd RV, Fothergill JL. The contribution of Pseudomonas aeruginosa virulence factors and host factors in the establishment of urinary tract infections. FEMS Microbiol Lett 2017;15:364(15). doi:https://doi.org/10. 1093/femsle/fnx124

82. Wagner VE, Bushnell D, Passador L, Brooks Al, Iglewski BH. Microarray analysis of Pseudomonas aeruginosa quorum-sensing regulons: effects of growth phase and environment. J Bacteriol. 2003;185(7):2080-95.

83. Cukier CD, Hope AG, Elamin AA, Moynie L, Schnell R, Schach S, Kneuper H, Singh M, Naismith JH, Lindqvist $Y$, Gray DW. Discovery of an allosteric inhibitor binding site in 3-OxO-acyl-ACP reductase from Pseudomonas aeruginosa. ACS Chem Biol. 2013;8(11):2518-27.

84. Meijler MM. Understanding the collective nose of bacteria. Cell Chem Biol. 2016;23(3):317-8

85. Singh PK, Schaefer AL, Parsek MR, Moninger TO, Welsh MJ, Greenberg EP. Quorum-sensing signals indicate that cystic fibrosis lungs are infected with bacterial biofilms. Nature. 2000;407(6805):762-4.

86. Zaborin A, Romanowski K, Gerdes S, Holbrook C, Lepine F, Long J, Poroyko V, Diggle SP, Wilke A, Righetti K, Morozova I. Red death in Caenorhabditis elegans caused by Pseudomonas aeruginosa PAO1. Proc Natl Acad Sci U S A. 2009;106(15):6327-32.

87. Rampioni G, Pustelny C, Fletcher MP, Wright VJ, Bruce M, Rumbaugh KP, Heeb S, Cámara M, Williams P. Transcriptomic analysis reveals a global alkylquinolone-independent regulatory role for PasE in facilitating the environmental adaptation of Pseudomonas aeruginosa to plant and animal hosts. Environ Microbiol. 2010;12(6):1659-73.

88. Hentzer $\mathrm{M}, \mathrm{Wu} \mathrm{H}$, Andersen JB, Riedel K, Homas B, Rasmussen TB, Bagge N, Kumar N, Schembri MA, Song Z, Krostoffersen P, Manefield M, Costerton JW, Molin S, Eberl L, Steinberg P, Kjelleberg S, Hoiby N, Givskov M. Attenuation of Pseudomonas aeruginosa virulence by quorum sensing inhibitors. EMBO J. 2003:22(15):3803-15

Ready to submit your research? Choose BMC and benefit from:

- fast, convenient online submission

- thorough peer review by experienced researchers in your field

- rapid publication on acceptance

- support for research data, including large and complex data types

- gold Open Access which fosters wider collaboration and increased citations

- maximum visibility for your research: over $100 \mathrm{M}$ website views per year

At $\mathrm{BMC}$, research is always in progress.

Learn more biomedcentral.com/submission 